\title{
Age-related Changes in Cortical Blood Flow Activation during Visual Processing of Faces and Location
}

\author{
Cheryl L. Grady, ${ }^{1}$ Jose Ma. Maisog, ${ }^{1, a}$ Barry Horwitz, ${ }^{1}$ Leslie G. Ungerleider, ${ }^{2}$ Marc J. Mentis, ${ }^{1}$ Judith A. Salerno, ${ }^{1}$ \\ Pietro Pietrini, ${ }^{1}$ Elizabeth Wagner, ${ }^{1}$ and James V. Haxby ${ }^{1, a}$ \\ ${ }^{1}$ Laboratory of Neurosciences, National Institute on Aging, Bethesda, Maryland 20892 and ${ }^{2}$ Laboratory of \\ Neuropsychology, National Institute of Mental Health, Bethesda, Maryland 20892
}

We examined age-related changes in object and spatial visual processing in two separate experiments. Regional cerebral blood flow (rCBF) was measured in young and old subjects with positron emission tomography and $\mathrm{H}_{2}{ }^{15} \mathrm{O}$ during tests of face matching, location matching, and a control task. The task demands in the two experiments were identical, but the stimuli in Experiment II were constructed to equalize stimulus complexity across all three tasks. The old subjects performed more slowly than the young subjects in both experiments, and showed significantly slower reaction times during location matching compared to face matching in Experiment II. Both young and old subjects showed occipitotemporal rCBF activation during face matching and occipitoparietal activation during location matching when these conditions were compared to the control task. However, in both experiments and in both tasks, young subjects showed greater activation of prestriate cortex (Brodmann's area 18), and old subjects had larger rCBF increases in occipitotemporal cortex (area 37). Areas in prefrontal cortex, as well as in inferior and medial parietal cortex, were more activated in the old subjects during location matching in both experiments. These results demonstrate that reliable age-related changes during visual processing can be found in rCBF patterns, suggesting more efficient use of occipital visual areas by younger subjects and more reliance by older subjects on one or more cortical networks, particularly for spatial vision, perhaps to compensate for reduced processing efficiency of occipital cortex. Both the differentially increased reaction times and the more widespread prefrontal activation in the old subjects during location matching suggest that spatial vision may be affected to a greater degree by aging than is object vision.

[Key words: cerebral blood flow, aging, neuroimaging, object vision, spatial vision, cortex]

Received Apr. 20, 1993; revised Aug. 24, 1993; accepted Sept. 9, 1993.

We thank Drs. Richard Frackowiack and Karl Friston for their generosity in providing us with SPM. We also acknowledge the following people for their expert technical assistance, without which these studies could not have been done: Jane Gillette, Kathryn Giacometti, and Kimberly Largay for the behavioral testing; Dr. Margaret Daube-Witherspoon for keeping the tomograph and automatic blood sampler working; Paul Baldwin, Gerard Jacobs, Stacey Stein, Shielah Green, Susan Fluck, Margaret Der, and Melvin Packer for data acquisition and processing; the staff of the NIH cyclotron facility for isotope production; and James Sullivan for assistance with the ALW computer network. Finally, we thank Drs. Mark Schapiro and Stanley Rapoport for their helpful comments on the manuscript.

Correspondence should be addressed to Cheryl L. Grady, Ph.D., NIA/LNS, Building 10, Room 6C414, 9000 Rockville Pike, Bethesda, MD 20892.

aPresent address: Functional Brain Imaging Section, Laboratory of Psychology and Psychopathology, National Institute of Mental Health, Bethesda, MD 20892. Copyright (c) 1994 Society for Neuroscience $0270-6474 / 94 / 141450-13 \$ 05.00 / 0$
Many visual functions have been found to be impaired in older subjects, including visual search (Plude and Hoyer, 1986), visuomotor tracking (Wickens et al., 1987), spatial integration (Salthouse, 1987), spatial localization in the presence of distractors (Sekuler and Ball, 1986), perception of faces (Sekuler and Owsley, 1982; Eslinger and Benton, 1983; Koss et al., 1991), recognition memory for faces (Bartlett et al., 1989), contrast sensitivity, especially to higher spatial frequencies (Sekuler and Owsley, 1982), and mental rotation of visual stimuli (Gaylord and Marsh, 1975; Berg et al., 1982; Herman and Bruce, 1983; Puglisi and Morrell, 1986). In almost all tasks that have been examined, older subjects perform more slowly than young subjects, and sometimes are less accurate. This age-related slowing of visual function has been interpreted as reduced processing efficiency or effectiveness (Salthouse, 1987). There is evidence to suggest that some types of visual processing, for example, spatial abilities, are more affected by age, or affected at an earlier age, than other abilities, both in humans (Salthouse, 1982; Koss et al., 1991) and in monkeys (Bachevalier et al., 1991). Others have suggested that there is a generalized slowing of all cognitive processes with age that is accentuated with increasing task complexity (e.g., Cerella, 1985), or that there is only slowing of perceptual-motor processes and changes in response bias (Strayer et al., 1987). However, there is no consensus that there is a generalized slowing with age, as some have reported results that do not fit this model (Sckuler and Ball, 1986; Allen et al., 1992).

Although age-related neuropathological changes have been found in the visual system, the neurobiological changes that underlie the reduced visual performance in older individuals remain obscure. There are numerous changes that occur with age in the lens and retina (for reviews, see Owsley and Sloane, 1990; Scheiber, 1992). There also is cell loss in occipital cortex with aging (Devaney and Johnson, 1980), and reduced activity of cholinergic and GABA neurotransmitter enzymes in the lateral geniculate and other thalamic nuclei (McGeer and McGeer, 1976). However, it is not clear what impact any of these changes have on specific visual functions.

One way to examine the neurobiology of age-related changes in visual processing is to use positron emission tomography (PET) and $\mathrm{H}_{2}{ }^{15} \mathrm{O}$ to measure regional cerebral blood flow (rCBF) in young and old subjects during performance of various visual tasks. Evidence from experiments in nonhuman primates (Ungerleider and Mishkin, 1982; Mishkin et al., 1983; Van Essen, 1985; Desimone and Ungerleider, 1989; Felleman and Van Essen, 1991) and from lesion studies in humans (Damasio et al., 1982, 1989; Posner et al., 1984; Mesulam, 1985; Iwata, 1989; Newcombe and Ratcliff, 1989; Vaina, 1989) has shown that there are two anatomically and functionally distinct pathways 


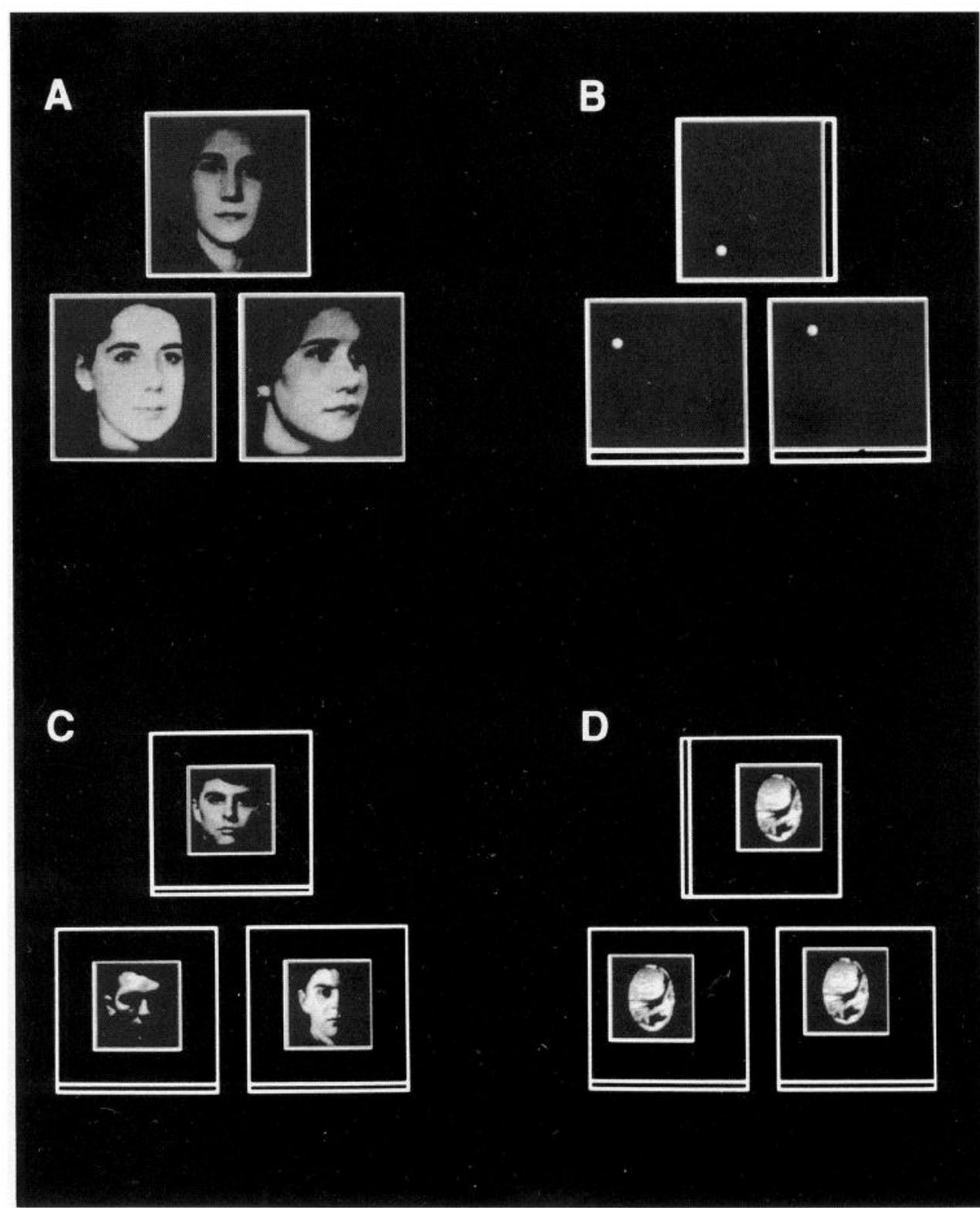

Figure 1. $A$ and $B(t o p)$ show the face and location stimuli for Experiment $\mathrm{I}$. The control task stimuli were three empty squares. $C$ and $D$ (bottom) show the face and location stimuli for Experiment II. The stimuli for the control task were three squares with the noise pattern (seen in the location stimuli on the bottom right) centered in the larger square. in extrastriate visual cortex, a ventral occipitotemporal pathway for the perception of objects and a dorsal occipitoparietal pathway for the perception of spatial relations among objects. Studies using PET to measure rCBF have demonstrated the ventral and dorsal visual streams in human cortex by showing task-specific activation of occipitotemporal rCBF during perception of faces (Haxby et al., 1991; Sergent et al., 1992), and of occipitoparietal cortex during spatial tasks (Roland et al., 1987; Haxby et al., 1991).

In a previous article (Grady et al., 1992) we examined the effects of aging on object and spatial vision (face and location matching) using PET and $\mathrm{H}_{2}{ }^{15} \mathrm{O}$, and found that old subjects showed a dissociation of rCBF activation as did the young subjects, that is, more activation in occipitotemporal cortex during face matching and more occipitoparietal activation during location matching. However, the old subjects also had ventral activation during location matching and dorsal activation during face perception that was not seen in the young subjects, and young subjects had more activation in ventral occipital cortex than did the old subjects. Thus, the two visual pathways were intact in older subjects, but were less functionally distinct. In addition, the older subjects showed the expected performance decrements in that they were as accurate as young subjects in these tasks, but performed more slowly. We suggested that this finding indicated a reduced processing efficiency and greater effort in stimulus processing in the older subjects that resulted in recruitment of cortex not activated in young subjects, thus increasing processing time and slowing reaction time.

The original study had several limitations, however, one of which was that the stimuli used in the face and location tasks were not equivalent in terms of complexity. The faces were more visually complex than the stimuli used for either the location or the control task. In addition, the anatomical precision of the analysis was relatively crude, and did not allow the localization of activated areas to specific gyri. The purpose of the present investigation, therefore, was to examine the neurobiological basis of age-related changes in object and spatial visual processing in greater detail. We have reanalyzed the data from the original 


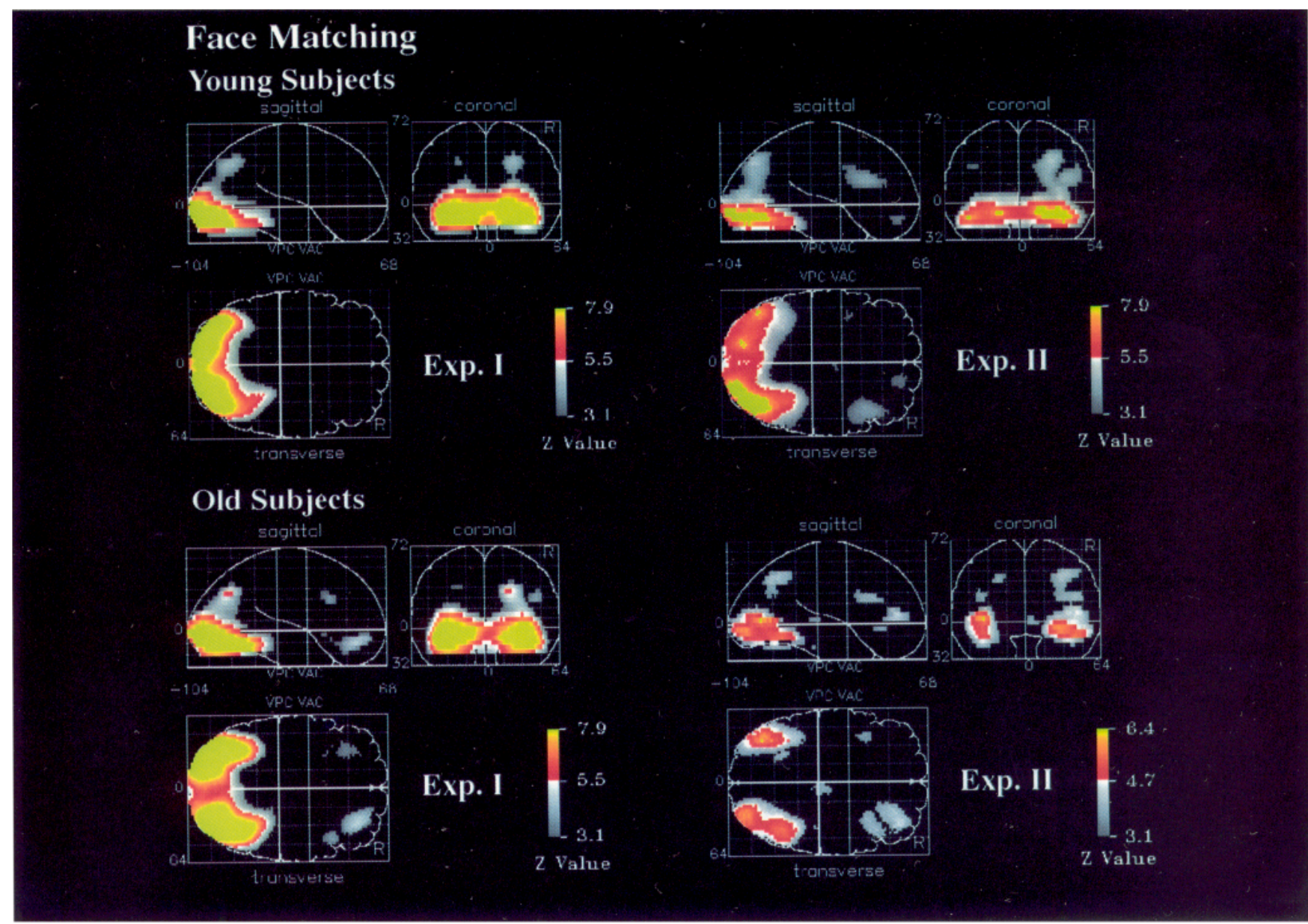

Figure 2. Areas of significant $\mathrm{rCBF}$ increase in young subjects (top) and old subjects (bottom) during face matching compared to the control task. Only voxels with a $p$ value of 0.001 or less are shown. The brain schematics are line-of-sight drawings showing pixels of greatest activation in the sagittal, coronal, and transverse planes. All voxels are in the stereotaxic space of Talairach and Tournoux (1988).

experiment, after adding additional subjects, and conducted a second experiment to address three issues: (1) equalization of stimulus complexity across all tasks to replicate our previous findings in a second sample of subjects, (2) comparison of agerelated changes in performance measures and $\mathrm{rCBF}$ activation patterns during face and location matching to determine whether spatial ability is more affected by aging, and (3) analysis of both experiments using a more anatomically precise image analysis system to better localize areas of activation.

\section{Materials and Methods}

Subjects. The subjects in both experiments were males screened for all diseases that might compromise brain function, such as cardiovascular disease, hypertension, head trauma, drug abuse, or psychiatric illness (Duara et al., 1984). Screening tests included ECG, EEG, magnetic resonance imaging of the brain, complete blood count, liver and thyroid function tests, and measurement of creatinine and cholesterol levels. Fifteen young (mean age \pm SD, $26 \pm 4$ years) and 17 old (67 \pm 6 years) subjects participated in Experiment I; 10 young and 8 old subjects from this experiment were described in a previous report (Grady et al., 1992). Nine young ( $27 \pm 3$ years) and 9 old ( $65 \pm 3$ years) subjects participated in Experiment II. All subjects were right-handed, and there were no differences in mean years of education among the four groups (one-way ANOVA, $F=1.4, p>0.05$ ).

Stimuli and tasks. Three tasks were performed by the subjects in experiments I and II: a sensorimotor control task, a face matching task, and a location matching task (Haxby et al., 1991; Grady et al., 1992). Sample items from the face and location matching tasks of Experiment
I are shown in Figure 1, $A$ and $B$. In the face matching task the subject was asked to indicate which of the two bottom squares contained a picture of the same person as shown in the top square (the faces were from the Benton facial recognition test; Benton, 1990). One of the bottom faces was a distractor and one was a picture of the person in the top square taken from a different angle or under different lighting conditions. The response consisted of pressing a button with either the right or left thumb, depending on whether the correct stimulus match was on the right or left side. In the location task, the subject indicated which bottom square had a dot in the same location relative to the double line as the dot in the top square. The position of the double line in the top square was rotated relative to the bottom squares. The sensorimotor control task consisted of three empty squares in the same configuration as in the matching tasks, and the subject was required simply to alternate right and left button presses in response to the presentation of the stimulus. Figure $1, C$ and $D$, shows examples of the stimuli used for face and location matching in Experiment II. The faces were the same as in Experiment I, but were contained in a small square centered inside a larger square; the task was the same as in Experiment I, to match one of the bottom faces with the top face. The stimuli for the location task consisted of a noise pattern inside a small square that was located in different positions within the larger square; the task was again to match the location of the inner object, relative to the double line, in the top square to that of one of the bottom squares. The control task consisted of the same noise pattern used in the location task but centered inside the larger square, and the task was to alternate button responses. The large squares in Experiment II all had a double line on one side of the square regardless of the task (unlike Experiment I, in which only the location matching squares had double lines).

All subjects were administered the tasks before the PET scan to ensure adequate learning of the tasks prior to $\mathrm{rCBF}$ measurement. Performance 


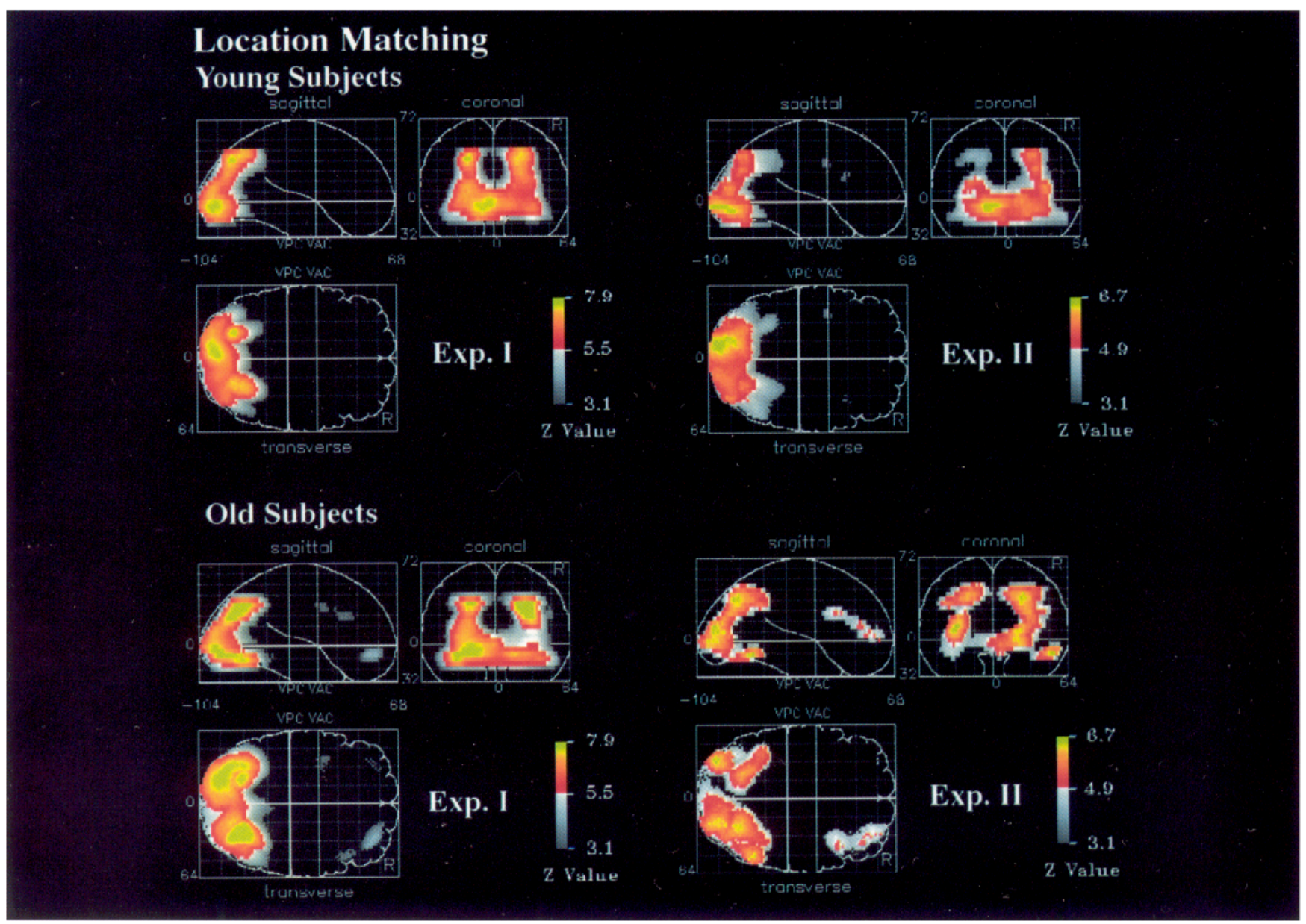

Figure 3. Areas of significant rCBF increase in young subjects (top) and old subjects (bottom) during location matching compared to the control task. Areas of activation are represented in the same manner as in Figure 2.

of all subjects was monitored during the task conditions (both pretesting and during the PET scans) by an Apple IIe computer that was used to control the presentation of the stimuli as well as record reaction times and accuracy. All subjects with less than $20 / 20$ vision uncorrected wore glasses during the scan, either their usual corrective lenses, or lenses custom-made to correct the subject's vision for the viewing distance used during the scanning session $(55 \mathrm{~cm})$.

PET procedure. The scans of Experiment I were performed using a Scanditronix PC1024-7B tomograph (Uppsala, Sweden), which has a reconstructed transverse resolution of $6.5 \mathrm{~mm}$ and an axial resolution of 10-12 mm. Data from seven slices were acquired simultaneously parallel to the inferior orbitomeatal (IOM) line, beginning at $15 \mathrm{~mm}$ above the IOM line, with a separation between planes of $14 \mathrm{~mm}$ (center to center). Experiment II utilized a Scanditronix PC2048-15B tomograph (Uppsala, Sweden), which has a reconstructed resolution of 6.5 $\mathrm{mm}$ in both transverse and axial planes. This tomograph allows 15 simultaneous planes to be acquired that are separated by $6.5 \mathrm{~mm}$ (center to center). Six studies were performed on each subject, separated by 12 min. In Experiment I $30 \mathrm{mCi}$ of $\mathrm{H}_{2}{ }^{15} \mathrm{O}$ was injected intravenously for each scan. In Experiment II, each injection contained $40 \mathrm{mCi}^{\circ} \mathrm{H}_{2}{ }^{15} \mathrm{O}$. Emission data were corrected for attenuation by means of a transmission scan obtained at the same levels as the emission scans. Head movement during the scans was minimized by using a thermoplastic mask that was molded to each subject's head and attached to the scanner bed.

In Experiment I each task was presented twice, with the control task presented during the first and last runs, and the face and location matching tasks presented in between, in an alternating sequence, with the order counterbalanced among subjects. In Experiment II the control task also was presented twice, but the face and location matching tasks were performed only once, with the order counterbalanced among subjects. The two remaining runs of Experiment II were designed to examine selective attention to faces or location, and are not included in the present analysis. Each task was begun $1 \mathrm{~min}$ prior to isotope injection and continued throughout the scanning period. Scanning was begun when the brain radioactive count rate reached a threshold value, and was continued for $4 \mathrm{~min}$. Arterial blood sampling was initiated at the time of injection and continued throughout the scanning period. Sixteen scans were obtained in this 4 min period: twelve $10 \mathrm{sec}$ scans, followed by four $30 \mathrm{sec}$ scans. The data from the 16 scans and the arterial timeactivity curve were used with either a weighted integration method (Experiment I; Alpert et al., 1984) or a rapid least squares method (Experiment II; Holden et al., 1981; Carson et al., 1987) to reconstruct one set of either 7 or 15 rCBF images for each task condition. The two reconstruction algorithms produce comparable results (Carson et al., 1987).

Data analysis. Reaction times and accuracy measures (percentage correct) were analyzed both within and across experiments using analyses of variance, with post hoc $t$ tests in case of significant interactions. Within-experiment comparisons were made using two-way ANOVAs for reaction time and accuracy with age group as the independent factor and task as the repeated measure. Between-experiment comparisons on the performance measures were carried out for the face matching and location matching separately, primarily to examine the effect of experiment and the interaction of age and experiment.

Image data from both experiments were analyzed using Statistical Parametric Mapping, or SPM (MRC Cyclotron Unit, Hammersmith Hospital; Friston et al., 1991a). The images were interpolated and stereotaxically normalized using a nonlinear transformation (Friston et al., $1989,1991 \mathrm{~b})$ to warp each three-dimensional image set into the stereotaxic space of Talairach and Tournoux (1988). Following stereotaxic normalization, an analysis of covariance (Friston et al., 1990) was applied voxel by voxel to remove global and intersubject effects (there 
Table 1. Performance data

\begin{tabular}{lllll} 
& \multicolumn{2}{l}{ Reaction time $(\mathrm{msec})$} & \multicolumn{2}{l}{ Percentage correct } \\
\cline { 2 - 3 } & Young Ss & Old Ss & Young Ss & Old Ss \\
\hline A. Experiment $\mathrm{I}^{a}$ & $1797 \pm 303$ & $2843 \pm 1315$ & $89 \pm 6$ & $83 \pm 10$ \\
$\quad$ Face matching & $2566 \pm 1094$ & $3273 \pm 1306$ & $87 \pm 11$ & $86 \pm 9$ \\
$\quad$ Location matching & & & & \\
B. Experiment II & & & & \\
$\quad$ Face matching & $2196 \pm 669$ & $3422 \pm 940$ & $81 \pm 9$ & $76 \pm 7$ \\
$\quad$ Location matching & $2372 \pm 531$ & $5583 \pm 1502$ & $92 \pm 6$ & $86 \pm 10$
\end{tabular}

a All values mean \pm SD. Significant main effect of age and task for RT. All effects NS for accuracy.

${ }^{b}$ All values mean + SD. Main effects of age and task, and interaction significant for RT. Significant main effect of task for accuracy.

were no significant global task effects for any group). Finally, $t$ statistics were computed for each voxel (Friston et al., 1991a) for the following comparisons: (1) facc and location matching minus the control task for both groups of young subjects ( $p<0.001$, one-tailed), (2) face and location matching minus the control task for both groups of old subjects ( $p<0.001$, one-tailed), (3) interaction of group and rCBF activation for face and location matching where old $>$ young and where young $>$ old ( $p<0.01$, one-tailed), that is, comparison of the matching task minus control task difference between age groups. Voxels with significant interactions are reported if they also showed significant within-group differences at $p<0.01$, resulting in $p<0.0001$ when considered conjointly. The results of the SPM analyses include z-values and coordinates in the atlas system for all voxels that were activated above control task levels during a specific task or that showed significant differences between groups in rCBF increases. Values of rCBF are expressed as $\mathrm{ml} /$ $100 \mathrm{gm} / \mathrm{min}$, adjusted using the ANCOVA and scaled to a mean of 50 .

Local maxima for each area of significant difference were computed for all comparisons. Local maxima were defined as voxels with larger $z$-values than all voxels within $1 \mathrm{~cm}$. Locations of maxima are reported in three-dimensional coordinates and in terms of gyrus and/or Brodmann's area (referred to as BA), as defined in the Talairach atlas.

\section{Results}

\section{Performance data}

The performance data for old and young subjects in both experiments are shown in Table 1. In Experiment $\mathrm{I}$, the main cffccts of age $(F=7.1, p<0.02)$ and task $(F=7.8, p<0.01)$ were significant for reaction time, indicating slower performance by the old subjects in both tasks, and slower performance by both groups on the location task. None of the comparisons showed a significant age-related difference in performance accuracy. In Experiment II there was a significant effect of age on reaction time $(F=42.6, p<0.0001)$, again indicating slower performance overall by the old subjects, and a significant effect of task $(F=13.7, p<0.002)$. However, the age $\times$ task interaction also was significant $(F=9.9, p<0.01)$, and post hoc $t$ tests showed a significant slowing in reaction time during location matching relative to face matching only in the old subjects $(t=3.6, p<0.01)$. For the accuracy measures of Experiment II, only the task effect was significant $(F=19.1, p<0.001)$ due to less accurate performance by both groups on the face matching task.

The effect of experiment on reaction time during face matching did not reach statistical significance $(F=3.2, p<0.08)$. However, there was a significant effect of experiment $(F=9.2$, $p<0.005)$ on location matching. The interaction of age and experiment also was significant $(F=12.9, p<0.001)$, indicating that only the old subjects had increased reaction time during location matching in Experiment II compared to the old subjects of Experiment I $(t-4.1, p<0.001)$. The effect of experiment on accuracy was not significant for location matching, but was significant for face matching $(F=9.6, p<0.005)$, with both age groups showing less accurate performance in Experiment II. The interaction of age and experiment was not significant.

\section{rCBF activation during face and location matching}

The areas that were significantly activated $(p<0.001)$ during face matching (compared to the control task) are shown for the young subjects of both experiments in Figure 2. In Experiment $\mathrm{I}$, increases in $\mathrm{rCBF}$ were seen primarily in ventral and lateral occipital cortex (BA 18 and 19) and in occipitotemporal cortex (BA 37) of both hemispheres, somewhat more on the right. Less intense activation was seen in right occipitoparietal cortex. During location matching (Fig. 3), the young subjects in Experiment I showed areas of activation bilaterally in ventral and lateral occipital cortex, which did not extend as far anterior as was seen during face matching, and large activations in occipitoparietal cortex bilaterally, in BA 19 and extending into superior parietal cortex (BA 7). In Experiment II (Figs. 2, 3), the young subjects showed essentially the same patterns of activation, except that $\mathrm{rCBF}$ activation was seen in right prefrontal cortex (including BA 46) in both tasks.

The areas of rCBF activation during face matching $(p<0.001)$ are shown for the old subjects of both experiments in Figure 2. As with the young subjects in Experiment I, the major areas of increase were in ventral and lateral occipital and occipitotemporal cortex (BA 18, 19, and 37), although there appeared to be less activation of medial occipital cortex than was seen in young subjects. There was an occipitoparietal region of activation in the right hemisphere, similar to that seen in the young subjects, and activation of prefrontal cortex bilaterally (including BA 46 in the right hemisphere). During location matching, the old subjects of Experiment I showed large areas of activation in dorsal regions of BA 19, extending up into BA 7 (Fig. 3, bottom). They also had bilateral areas of rCBF increase in ventral occipital cortex, although this activation extended somewhat more anteriorly than that seen during location matching in the young subjects. In addition, there were areas of bilateral activation in prefrontal cortex (including BA 46 in the right hemisphere) during location matching in the old subjects of Experiment $I$. The old subjects in Experiment II (Figs. 2, 3) showed patterns of activation during face and location matching that were very similar to those of the old subjects in the first experiment.

Thus, in both experiments, young and old subjects show similar patterns of rCBF activation during the two matching tasks, compared to the control task, that is, ventral occipital and occipitotemporal activation during face matching and dorsal occipital and parietal activation during location matching. Young 


\begin{tabular}{|c|c|c|c|c|c|c|c|}
\hline Region, gyrus & BA & $\mathrm{R} / \mathrm{L}$ & $\mathrm{A} / \mathbf{P}$ & $\mathrm{S} / \mathrm{I}$ & Y Diff & O Diff & $\mathrm{Z}$ \\
\hline \multicolumn{8}{|c|}{ A. Face matching-greater rCBF activation in young subjects } \\
\hline 1. Lingual & 18 & 4 & -96 & -4 & $5.19^{* *}$ & $2.18^{* *}$ & 3.91 \\
\hline \multicolumn{8}{|c|}{ B. Face matching-greater rCBF reductions in old subjects } \\
\hline 2. Postcentral & $1 / 2$ & -42 & -22 & 44 & 0.02 & $-3.63^{++}$ & 3.86 \\
\hline 3. Precentral & 4 & 22 & -16 & 44 & 0.25 & $-2.26^{++}$ & 2.46 \\
\hline 4. Cingulate & 32 & -4 & 4 & 44 & 0.39 & $-2.81^{++}$ & 2.77 \\
\hline 5. Cingulate & 32 & 16 & 2 & 44 & 0.59 & $-1.92^{+}$ & 2.41 \\
\hline 6. Insula & & 34 & 2 & 12 & -0.04 & $-2.58^{++}$ & 2.80 \\
\hline \multicolumn{8}{|c|}{ C. Location matching-greater rCBF activation in young subjects } \\
\hline 7. Lingual & 18 & -2 & -90 & -4 & $5.11^{* *}$ & $2.78^{* *}$ & 2.92 \\
\hline 8. Lingual & 18 & 22 & -64 & 4 & $2.66^{* *}$ & 0.73 & 2.73 \\
\hline 9. Cuneus & 18 & 10 & -74 & 20 & $2.45^{* *}$ & 0.01 & 3.23 \\
\hline \multicolumn{8}{|c|}{ D. Location matching-greater $\mathrm{rCBF}$ reductions in old subjects } \\
\hline 10. Postcentral & 2 & 32 & -18 & 28 & 0.79 & $-1.44^{++}$ & 3.19 \\
\hline 11. Sup. temporal & 22 & -52 & -28 & 4 & $-1.55^{+}$ & $-3.39^{++}$ & 2.72 \\
\hline 12. Sup. temporal & 22 & 52 & -26 & 4 & $-1.19^{+}$ & $-3.24^{++}$ & 2.93 \\
\hline 13. Insula & & -24 & -4 & 16 & 0.85 & $-1.52^{++}$ & 2.95 \\
\hline 14. Insula & & 30 & -14 & 16 & 0.31 & $-1.92^{++}$ & 2.92 \\
\hline
\end{tabular}

Coordinates and Brodmann's areas from Talairach and Tournoux (1988). R/L (right/left) coordinate (X), negative indicates left hemisphere; $A / P$ (anterior/posterior) coordinate $(Y)$, negative indicates posterior to the zero point (located at the anterior commissure); S/I (superior/inferior) coordinate (Z), negative indicates inferior to the AC-PC line; BA, Brodmann's area; Y Diff, matching task rCBF minus control task $\mathrm{rCBF}$ in young subjects (values in $\mathrm{ml} / 100 \mathrm{gm} / \mathrm{min}$ ANCOVA-adjusted and scaled to a mean of 50); O Diff = matching task minus control task rCBF in old subjects (same units as for young subjects); $Z, Z$ of the between-group difference. Significant activation above control task (within-group comparison): ${ }^{*}, p<0.01 ;{ }^{* *}, p<0.001$. Significant reduction below control task (within-group comparison): ${ }^{+}, p<$ $0.01 ;^{++}, p<0.001$.

subjects appeared to have more medial occipital activation in both experiments, and old subjects to have more frontal activation. In the next sections, the activation patterns of the two age groups are compared directly.

\section{Age group comparisons of $\mathrm{CBF}$ activation}

Figures 4 and 5 show the cortical areas where there was a significant age-related difference in $\mathrm{rCBF}$ activation $(p<0.01)$, and where either or both groups of subjects showed a significant change in the matching task compared to the control task ( $p<$ 0.01 ). Tables $2-5$ show the coordinates of the local maxima in these cortical areas. In Experiment I, during face matching, the young subjects had greater rCBF activation in medial occipital cortex bilaterally (Fig. 4), with the maximum between-group difference in a region of the right lingual gyrus (BA 18, Table $2 A$ ). In addition, there were areas that did not show increased rCBF during face matching in young subjects, but did show reduced $\mathrm{rCBF}$ in old subjects, including cortex near the central sulcus, right insula, and the anterior cingulate bilaterally (Fig. 4 , Table $2 B$ ). During location matching, young subjects again had more rCBF activation compared to old subjects in the lingual gyrus bilaterally, and also in the cuneus (BA 18, Fig. 5, Table $2 C$ ). The old subjects had greater reductions in $\mathrm{rCBF}$ during location matching in the superior temporal and postcentral gyri, and in the insula bilaterally (Table $2 D$ ).

During face matching, the old subjects in Experiment I (Fig. 4 , Table $3 A$ ) had more rCBF activation in the fusiform gyrus bilaterally (BA 37), left middle temporal gyrus (BA 37), bilateral inferior frontal gyri (BA 47), extending back to the insula on the left, and bilateral dorsolateral prefrontal cortex (BA 46). There also were areas where the young subjects showed greater $\mathrm{rCBF}$ reductions during face matching, compared to the old subjects, in bilateral prefrontal cortex (in areas inferior or anterior to those where old subjects showed more activation), left medial parietal cortex, and right anterior cingulate (Fig. 4, Table $3 B$ ). During location matching (Fig. 5, Table $3 C$ ), the old subjects had more rCBF activation in bilateral fusiform gyri (BA 37), left occipitotemporal cortex extending up into inferior parietal cortex, bilateral prefrontal cortex (in BA 8, 10, and 47), and left medial parictal cortcx (BA 7). During this task the young subjects had greater rCBF reductions in the left superior temporal gyrus (BA 39), left prefrontal and right inferior parietal cortex (Fig. 5, Table 3D).

In Experiment II (Fig. 4, Table $4 A$ ) the young subjects showed more rCBF activation during face matching primarily in extensive areas of occipital cortex, with maxima in the posterior portions of the fusiform and lingual gyri and cuneus bilaterally (BA 18 and 19). During location matching (Fig. 5, Table 4B), there again were large areas of occipital cortex that showed greater activation in young subjects, with the maximum difference in the left lingual gyrus near the midline, and one region in the precentral gyrus of each hemisphere. During this task, there were bilateral regions of cingulate cortex where the old subjects had reduced $\mathrm{rCBF}$, accounting for the group difference (Table $4 C$ ).

Old subjects in Experiment II had a greater rCBF increase compared to the young subjects during face matching in only one area, in BA 37 of the left hemisphere (Fig. 4, Table $5 A$ ). The remaining areas with significant between-group differences were due to greater reductions in $\mathrm{rCBF}$ in the young subjects (Iable $5 B$ ). These were in the superior temporal gyri, left prefrontal cortex, and right inferior parietal cortex. During location matching in Expcrimcnt II (Fig. 5, Table 5C), the old subjects had larger rCBF increases in bilateral fusiform gyri (BA 37), left 




Figure 4. Cortical areas of significant $(p<0.01)$ between-group interactions during face matching are shown on lateral and medial schematics of each hemisphere. Voxels shown also had significant $(p<0.01)$ rCBF change in either or both within-group comparisons. $I$, Experiment I; $I I$, Experiment II. Red areas are those where young subjects had greater rCBF increases (face matching vs control task) than did the old subjects. Green areas represent cortex that showed significantly more reduction of $\mathrm{rCBF}$ in the old subjects during face matching. Yellow and blue areas represent the inverse conditions, that is, yellow for those areas where old subjects had greater rCBF increases than did the young subjects, and blue for those areas of more reduced $\mathrm{rCBF}$ in the young subjects during face matching.

medial parietal cortex (BA 7), bilateral prefrontal cortex (BA 8 and 46 in the left hemisphere and BA 10 in the right), and bilateral inferior parietal cortex (BA 40). Between-group differences due to greater $\mathrm{rCBF}$ reductions in young subjects during location matching were seen in the bilateral superior temporal cortex (more on the left), prefrontal cortex (BA 10 in the left hemisphere and BA 8 in the right), and posterior cingulate cortex (Fig. 5, Table 5D).

The age-related differences in $\mathrm{rCBF}$ that were common to both experiments were as follows. In both experiments, the young subjects had more activation in ventral and medial occipital cortex during both tasks than did the old subjects, primarily in prestriate BA 18 . The old subjects of both experiments showed greater activation of $\mathrm{rCBF}$ in occipitotemporal cortex in both tasks, in the left hemisphere during face matching and bilaterally during location matching. In addition, there was an age-related change in or near BA 46 in the left hemisphere in both tasks and both experiments, where either the old subjects showed greater rCBF activation or the young subjects showed reduced $\mathrm{rCBF}$. During location matching in both experiments there were bilateral areas of cortex near the central sulcus where old subjects showed reductions in $\mathrm{rCBF}$ whereas young subjects showed no change or increased rCBF. Also during location matching, the old subjects in both experiments had more activation in several areas of prefrontal cortex (generally dorsolateral in the left hemisphere and ventrolateral in the right hemisphere), in bilateral inferior parietal cortex, and in left medial parietal cortex. Finally, in both tasks and both experiments, there were regions that showed significant age-related differences due to rCBF reductions in the young subjects. These were generally in bilateral superior temporal cortex and left prefrontal cortex.

\section{Discussion}

These experiments demonstrate two main results. First, we have shown in the first experiment, and have replicated the finding in the second experiment, that object and spatial visual processing in both young and old subjects activate occipitotemporal and occipitoparietal cortex, respectively. These activation patterns show that visual processing in the human brain is organized into ventral and dorsal processing streams similar to those identified in nonhuman primates. One possible confound of these results is that eye movements were not controlled in either experiment, and the possibility of differential eye movements 


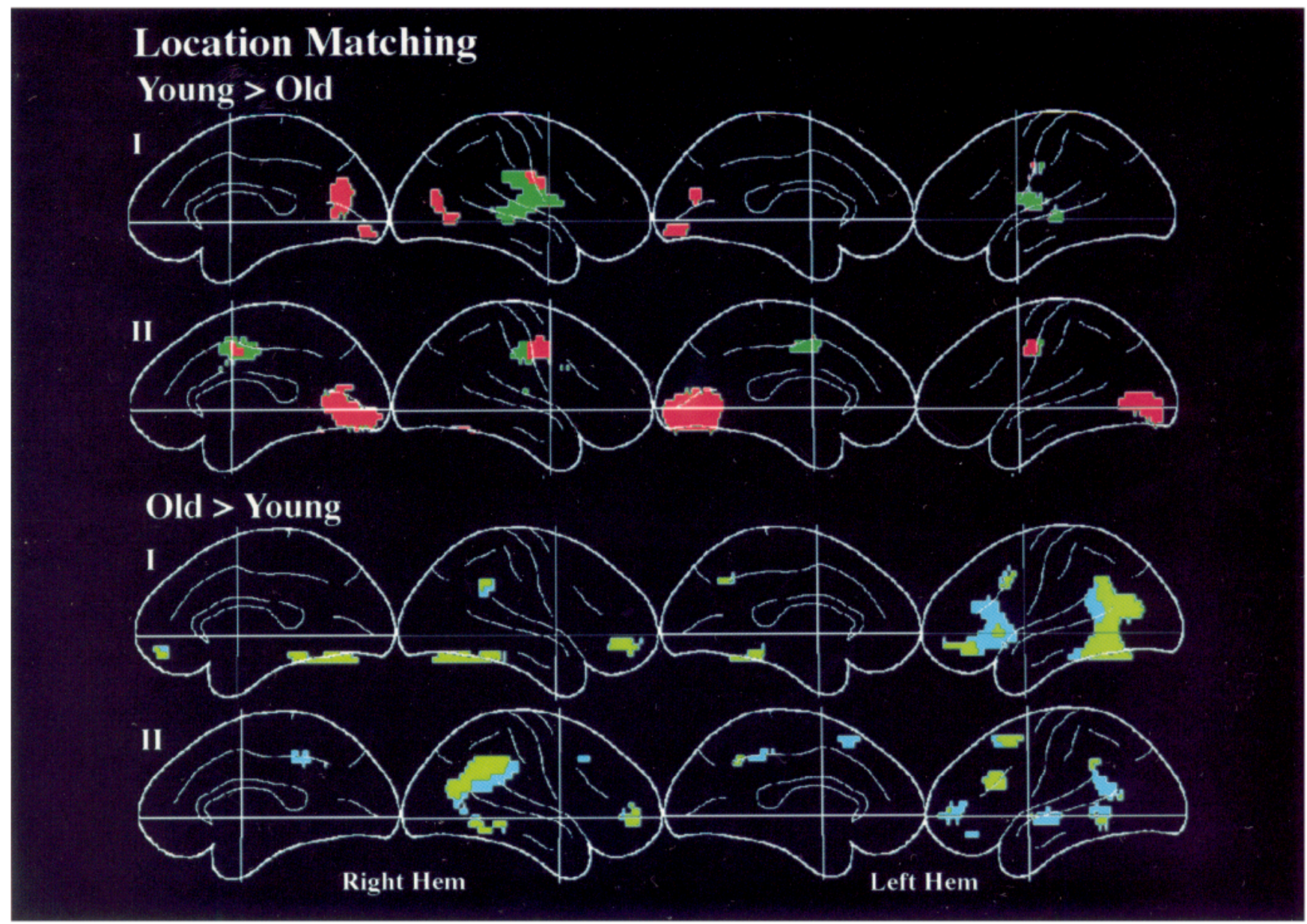

Figure 5. Cortical areas of significant $(p<0.01)$ between-group interactions during location matching. Voxels shown also had significant $(p<$ $0.01) \mathrm{rCBF}$ change in either or both within-group comparisons. Colored areas indicate the same conditions as in Figure 4.

in the two tasks cannot be ruled out. However, it is unlikely that eye movements contributed in a significant way to the rCBF increases observed in our experiments since voluntary saccades have recently been reported (Petit et al., 1993) to result in $\mathrm{rCBF}$ changes primarily in the precentral gyrus, supplementary motor area, cingulate cortex, and subcortical nuclei, regions that were not differentially active in the face or location matching task.

The second main finding of these two experiments is that robust and reliable age-related changes during visual processing can be found in both performance measures and rCBF. In addition, the results reported here support and extend our earlier article (Grady et al., 1992) in which we reported qualitatively similar findings using different analysis techniques. Young subjects in both experiments showed more activation of prestriate cortex compared to old subjects. Those areas that were more activated in young subjects were posterior and medial to the occipital areas reported by Haxby et al. (1993) as being specific to either face or location matching, but were similar in location to areas in the lingual gyrus found to be activated during the discrimination of sine wave gratings (Sergent et al., 1992). These foci in the lingual gyrus probably process the low-level aspects of visual stimuli, and are likely to be a part of the pathway before the bifurcation of visual processing into ventral and dorsal streams. Old subjects showed more activation in areas outside occipital cortex, some of which were extrastriate visual areas (e.g., occipitotemporal), and some of which were in regions of cortex whose roles in visual processing are less well known (e.g., medial and inferior parietal cortex). The foci in area 37 that showed more activation in the old subjects of both experiments during face matching were several centimeters lateral and superior to the foci in area 37 of the fusiform gyrus that are activated selectively during face matching in young subjects (Sergent et al., 1992; Haxby et al., 1993). However, those foci that were more activated in old subjects during location matching were in ventral regions of area 37 and therefore closer in location to face-specific regions in the fusiform gyrus (less than $2 \mathrm{~cm}$ ). These foci may or may not be the same functional area of cortex, but if so, this would be consistent with our previous hypothesis that location matching in old subjects involves more activation of face-specific areas (Grady et al., 1992). Old subjects also showed more activation of areas in lateral prefrontal cortex, particularly during location matching, that may be homologous to regions that are the frontal projection fields of parietal and temporal visual cortex in monkeys (Cavada and Goldman-Rakic, 1989; Ungerleider et al., 1989; Barbas, 1992). This pattern of differences suggests more efficient use of occipital visual areas by younger subjects and more reliance by older subjects on areas either farther along in the two visual pathways, including frontal cortex, or areas outside these pathways. Reduced processing efficiency in prestriate occipital cortex (i.e., area 18) of older 
Table 3. Maxima of cortical regions where the task-control difference is greater in old subjects than in young subjects for Experiment $I$

\begin{tabular}{|c|c|c|c|c|c|c|c|}
\hline Region, gyrus & BA & $\mathrm{R} / \mathrm{L}$ & $\mathbf{A} / \mathbf{P}$ & $\mathrm{S} / \mathrm{I}$ & O Diff & Y Diff & $\mathrm{Z}$ \\
\hline \multicolumn{8}{|c|}{ A. Face matching-greater rCBF activation in old subjects } \\
\hline 1. Fusiform & 37 & -40 & -48 & -12 & $4.24^{* *}$ & 0.79 & 4.38 \\
\hline 2. Fusiform & 37 & 46 & -58 & -12 & $4.34^{* *}$ & $2.20^{* *}$ & 3.12 \\
\hline 3. Middle temporal & 37 & -36 & -58 & 4 & $2.04 * *$ & -0.45 & 3.75 \\
\hline 4. Inferior frontal & 47 & -30 & 38 & -12 & $2.12^{* *}$ & -1.22 & 3.18 \\
\hline 5. Inferior frontal & 47 & 34 & 40 & -12 & $3.20^{* * *}$ & 0.08 & 3.20 \\
\hline 6. Middle frontal & 46 & 48 & 20 & 24 & $1.23^{* *}$ & -0.54 & 3.19 \\
\hline 7. Insula & & -26 & 18 & -4 & $1.28^{*}$ & -1.20 & 3.08 \\
\hline \multicolumn{8}{|c|}{ B. Face matching-greater rCBF reductions in young subjects } \\
\hline 8. Middle frontal & $46 / 9$ & -38 & 18 & 24 & 0.88 & $-1.71^{+}$ & 3.29 \\
\hline 9. Superior frontal & 9 & 20 & 52 & 28 & -0.42 & $-2.09^{++}$ & 2.80 \\
\hline 10. Precuneus & 7 & -2 & -60 & 32 & -0.26 & $-2.02^{++}$ & 2.64 \\
\hline 11. Cingulate & 32 & 10 & 28 & 32 & -0.37 & $-2.18^{++}$ & 2.55 \\
\hline \multicolumn{8}{|c|}{ C. Location matching-greater rCBF activation in old subjects } \\
\hline 12. Fusiform & 37 & 32 & 52 & 12 & $3.73^{* *}$ & 0.29 & 4.41 \\
\hline 13. Fusiform & 37 & 30 & -44 & -16 & $2.16^{* *}$ & -0.46 & 3.14 \\
\hline 14. Middle occipital & 19 & -40 & -74 & 16 & $1.70^{* *}$ & -0.22 & 3.35 \\
\hline 15. Middle frontal & 10 & 18 & 56 & -8 & $1.61^{* *}$ & -0.79 & 2.88 \\
\hline 16. Middle frontal & 8 & -36 & 12 & 36 & $1.19^{*}$ & -0.83 & 2.78 \\
\hline 17. Inferior frontal & 47 & 38 & 42 & -8 & $2.23^{* *}$ & 0.03 & 2.77 \\
\hline 18. Precuneus & 7 & -8 & -58 & 36 & $1.12^{*}$ & -0.85 & 2.84 \\
\hline 19. Inf. fron./insula & & -32 & 14 & 0 & $1.12^{*}$ & $-1.72^{+}$ & 3.42 \\
\hline \multicolumn{8}{|c|}{ D. Location matching-greater $\mathrm{rCBF}$ reductions in young subjects } \\
\hline 20. Superior temporal & 39 & -38 & -50 & 20 & -0.54 & $-2.65^{++}$ & 3.10 \\
\hline 21. Middle frontal & 46 & -36 & 30 & 16 & 0.06 & $-1.69^{++}$ & 2.59 \\
\hline 22. Inferior frontal & 47 & -34 & 26 & -4 & 0.63 & $-2.17^{++}$ & 3.33 \\
\hline 23. Inferior parietal & 40 & 50 & -44 & 32 & -0.15 & $-1.95^{++}$ & 2.74 \\
\hline
\end{tabular}

Coordinates and Brodmann's areas from Talairach and Tournoux (1988). R/L (right/left) coordinate (X), negative indicates left hemisphere; $\mathrm{A} / \mathrm{P}$ (anterior/posterior) coordinate $(\mathrm{Y})$, negative indicates posterior to the zero point (located at the anterior commissure); S/I (superior/inferior) coordinate (Z), negative indicates inferior to the $\mathrm{AC}-\mathrm{PC}$ line; $\mathrm{BA}$, Brodmann's area; Y Diff, matching task rCBF minus control task rCBF in young subjects (values in $\mathrm{mV} / 100 \mathrm{gm} / \mathrm{min}$ ANCOVA-adjusted and scaled to a mean of 50); $\mathrm{O}$ Diff $=$ matching task minus control task rCBF in old subjects (same units as for young subjects); $Z, Z$ of the between-group difference. Significant activation above control task (within-group comparison): ${ }^{*}, p<0.01 ; * *, p<0.001$. Significant reduction below control task (within-group comparison): ${ }^{+}, p<$ $0.01{ }^{++}, p<0.001$

subjects may lead to recruitment of these other cortical regions (e.g., area 37 or frontal cortex). Activation of these additional areas of cortex also may explain the slowing of reaction time in older subjects, due to the additional time necessary for the information processing carried out by these areas.

\section{Changes in performance related to experiment and age}

The similarity of the rCBF activation patterns during face and location matching between the two experiments indicates that the ventral versus dorsal activation of $\mathrm{rCBF}$ originally reported with these tasks was due to the differential effects of the visual processing of faces versus location, and not to differences in stimulus complexity between the face and location stimuli in Experiment I. However, the processing of the stimuli in the two experiments was not identical, because the old subjects in Experiment II performed more slowly on the location matching task than their Experiment I counterparts, and there was a similar trend in both age groups for performance to be slower during face matching. In addition, accuracy on the face matching task was reduced for both groups in the second experiment. These results suggest that processing of the stimuli in Experiment II may have been more difficult than that of the stimuli in Experiment I. Differences between the two sets of stimuli that may have contributed to this increased difficulty include the smaller size of the faces in Experiment II, and the fact that all estimated distances in the location task of Experiment I were to the same reference point (a dot), but were to different reference points in Experiment II (two sides of the small square).

The old subjects performed more slowly than the young subjects overall, and were differentially affected by the changes made in Experiment II, showing slower reaction times during location matching compared to their times during face matching and compared to the reaction times of the old subjects in Experiment I, whereas the young subjects showed equivalent performance. This effect on reaction time, in conjunction with the finding that there were more brain regions with age-related changes in rCBF patterns during location matching compared to face matching, might suggest that the spatial vision pathway is more affected by the aging process than the object vision pathway, and would argue against a generalized slowing due to age. Other evidence for the differential effect of aging on the visual system includes the report by Sekuler and Ball (1986) that old subjects' errors increased during performance of a radial localization task as the target became more eccentric, that is, moved farther into the peripheral visual field. This suggests that processing depending on peripheral vision, which is preferen- 
Table 4. Maxima of cortical regions where the task-control difference is greater in young subjects than in old subjects for Experiment II

\begin{tabular}{lrrrrrrr} 
Region, gyrus & BA & $\mathrm{R} / \mathrm{L}$ & $\mathrm{A} / \mathrm{P}$ & $\mathrm{S} / \mathrm{I}$ & $\mathrm{Y}$ Diff & O Diff & $\mathrm{Z}$ \\
\hline A. Face matching-greater rCBF & activation in young subjects & & & & \\
1. Fusiform & 19 & -26 & -68 & -12 & $7.43^{* *}$ & $4.35^{* *}$ & 3.13 \\
2. Fusiform & 19 & -18 & -62 & -8 & $3.83^{* *}$ & 1.96 & 3.21 \\
3. Lingual & 18 & -6 & -78 & -4 & $6.66^{* *}$ & 1.65 & 3.75 \\
4. Lingual & 19 & -20 & -58 & 0 & $2.46^{* *}$ & 0.72 & 3.09 \\
5. Lingual & 18 & -2 & -90 & 0 & $6.62^{* *}$ & 1.47 & 3.82 \\
6. Lingual & 18 & 14 & -88 & -8 & $9.10^{* *}$ & 3.35 & 3.42 \\
7. Cuneus & 18 & -18 & -72 & 8 & $3.37^{*}$ & 0.79 & 3.04 \\
8. Cuncus & 18 & 12 & -74 & 20 & $2.06^{*}$ & -0.79 & 2.60 \\
9. Precentral & 6 & 44 & 4 & 28 & $3.85^{*}$ & 0.88 & 2.34 \\
B. Location matching-greater rCBF activation in young subjects & & & \\
10. Lingual & 18 & -6 & -82 & 0 & $8.17^{* *}$ & $2.64^{*}$ & 4.40 \\
11. Prccentral & 4 & 36 & 10 & 40 & $2.17^{*}$ & 0.99 & 2.70 \\
12. Precentral & 4 & 24 & -10 & 40 & $3.82^{* *}$ & -0.81 & 3.60 \\
C. Location matching & greater rCBF reductions in old subjects & & & \\
13. Cingulate & 24 & -12 & -6 & 40 & 0.28 & $-2.98^{++}$ & 2.90 \\
14. Cingulate & 24 & 14 & 8 & 28 & 0.27 & $-2.27^{+}$ & 2.40 \\
15. Cingulate & 32 & 6 & 4 & 44 & 1.36 & $-2.95^{++}$ & 2.80
\end{tabular}

Coordinates and Brodmann's areas from Talairach and Tournoux (1988). R/L (right/left) coordinate (X), negative indicates left hemisphere; $\mathrm{A} / \mathrm{P}$ (anterior/posterior) coordinate (Y), negative indicates posterior to the zero point (located at the anterior commissure); $\mathrm{S} / \mathrm{I}$ (superior/inferior) coordinate $(\mathrm{Z})$, negative indicates indicates inferior to the $\mathrm{AC}-\mathrm{PC}$ line; BA, Brodmann's area; Y Diff, matching task rCBF minus control task rCBF in young subjects (values in ml/100 $\mathrm{gm} / \mathrm{min}$ ANCOVA-adjusted and scaled to a mean of 50); O Diff = matching task minus control task rCBF in old subjects (same units as for young subjects); $\mathrm{Z}, \mathrm{Z}$ of the between-group difference. Significant activation above control task (withingroup comparison): ${ }^{*}, p<0.01 ;^{* *}, p<0.001$. Significant reduction below control task (within-group comparison): ${ }^{+}$ $p<0.01 ;^{++}, p<0.001$.

tially represented in dorsal stream regions (Ungerleider and Desimone, 1986; Baizer et al., 1991), is more vulnerable to aging than foveal vision, which is preferentially represented in ventral stream regions (Desimone et al., 1984; Baizer et al., 1991). Differential aging in extrastriate cortex also has been suggested by work in monkeys, who show deterioration of spatial performance at an earlier age, relative to other visual tasks (Rapp and Amaral, 1989; Bachevalier et al., 1991). An alternative explanation that cannot as yet be ruled out is that the location task may be a more complex or difficult task in both young and old subjects, and may thus be more affected by any generalized slowing (Cerella, 1985). The subjects' performance does not clearly indicate that the location tasks used in these experiments were consistently more difficult; nevertheless, this issue needs to be examined with a variety of object and spatial visual tasks.

\section{General versus task-specific changes in rCBF activation with age}

Although some of the age-related differences in rCBF activation were specific to location matching, others were similar across tasks, suggesting that there also are some general effects of aging on visual processing. In addition to those discussed above, the finding of age-related changes in activation of prefrontal cortex, specifically area 46 , is of interest given the current focus on the role of this area of cortex in working memory. Although the concept of working memory is defined somewhat differently in the human and animal literatures (Goldman-Rakic, 1987, 1990; Fuster, 1990; Baddeley, 1992), frontal cortex plays a key role in both. Performance on working memory tasks in monkeys is severely impaired after lesions of areas 46 and 9 around the principal sulcus (e.g., Rosvold et al., 1961; Goldman et al., 1971; Passingham, 1975; Goldman-Rakic, 1987), as is performance on analogous tasks in humans after frontal lobe damage (Milner and Petrides, 1984; Freedman and Oscar-Berman, 1986). In addition, human PET studies have shown activation of area 46 during verbal working memory tasks (Petrides et al., 1993), and during task conditions where the behavior is based on an internal representation rather than being stimulus driven, and thus are similar to working memory tasks (Petersen et al., 1989; Frith ct al., 1991). Although our visual tasks did not explicitly invoke working memory, the age-related changes in rCBF activation of area 46 in the left hemisphere that were found may indicate that these visual tasks place more of a demand on some aspect of working memory in old subjects than in young. For example, old subjects may need to make greater use of the central executive in perceptual tasks in order to organize the various elements of task performance. This could result in a reduction of working memory capacity when further demands are placed on prefrontal cortex, and result in poorer performance by old subjects during tasks that specifically stress working memory (e.g., Craik et al., 1990).

Another age-related change that was common to both face and location matching was the numerous areas of cortex where the young subjects showed reductions in rCBF during the matching tasks and the old subjects did not, which were primarily in prefrontal, and perisylvian cortex. These reductions may reflect a suppression of flow in these areas as a mechanism for focusing attention on these visual tasks in the young subjects. A similar phenomenon was reported by Roland (1982) in a group of subjects (of unspecified age) performing a task of selectively attending to one of three sensory modalities. In his experiment, direction of attention elsewhere caused a reduction or absence of the rCBF increase to auditory and visual stimuli in auditory and visual brain regions. A similar effect on the rCBF in left 
Table 5. Coordinates of cortical foci where the task-control difference is greater in old subjects than in young subjects for Experiment II

\begin{tabular}{|c|c|c|c|c|c|c|c|}
\hline Region, gyrus & $\mathrm{BA}$ & $\mathrm{R} / \mathrm{L}$ & $\mathrm{A} / \mathrm{P}$ & $\mathrm{S} / \mathrm{I}$ & O Diff & Y Diff & $\mathrm{Z}$ \\
\hline \multicolumn{8}{|c|}{ A. Face matching-greater rCBF activation in old subjects } \\
\hline 1. Inferior temporal & 37 & -48 & -68 & 4 & $2.42^{* *}$ & -0.59 & 3.85 \\
\hline \multicolumn{8}{|c|}{ B. Face matching-greater $\mathrm{rCBF}$ reductions in young subjects } \\
\hline 2. Middle temporal & 37 & -52 & -56 & 4 & -0.63 & $-3.19^{++}$ & 3.67 \\
\hline 3. Superior temporal & 39 & 40 & -54 & 20 & 0.06 & $-3.07^{++}$ & 2.80 \\
\hline 4. Superior temporal & 42 & -48 & -24 & 8 & $-2.48^{+}$ & $-5.72^{++}$ & 3.55 \\
\hline 5. Superior temporal & 22 & -52 & -36 & 16 & $-3.36^{+}$ & $-6.28^{++}$ & 3.06 \\
\hline 6. Middle frontal & 8 & -26 & 18 & 48 & 0.48 & $-3.18^{+}$ & 2.63 \\
\hline 7. Inferior frontal & $44 / 45$ & -44 & 16 & 16 & 0.84 & $-2.18^{+}$ & 2.82 \\
\hline 8. Medial frontal & 9 & -2 & 42 & 28 & 0.55 & $-2.55^{+}$ & 2.59 \\
\hline 9. Medial frontal & 6 & 10 & -22 & 52 & -0.51 & $-4.96^{++}$ & 2.71 \\
\hline 10. Medial frontal & 6 & -14 & -20 & 52 & 0.12 & $-4.58^{++}$ & 2.77 \\
\hline 11. Inferior parietal & 40 & 48 & -36 & 24 & $-3.15^{++}$ & $-6.99^{++}$ & 2.57 \\
\hline \multicolumn{8}{|c|}{ C. Location matching - greater rCBF activation in old subjects } \\
\hline 12. Fusiform & 37 & -40 & -48 & -4 & $1.67^{*}$ & -0.63 & 2.66 \\
\hline 13. Fusiform & 36 & 34 & -38 & -4 & $1.42^{*}$ & -0.99 & 2.72 \\
\hline 14. Inferior temporal & 37 & 52 & -52 & -8 & $3.29^{* *}$ & 0.61 & 2.62 \\
\hline 15. Middle temporal & 39 & 40 & -62 & 24 & $2.53^{*}$ & -1.04 & 3.17 \\
\hline 16. Middle frontal & 10 & 38 & 48 & 0 & $0.76^{*}$ & $-1.18^{+}$ & 3.30 \\
\hline 17. Middle frontal & 46 & -42 & 28 & 24 & $2.99 * *$ & -0.25 & 3.02 \\
\hline 18. Middle frontal & $6 / 8$ & -26 & 12 & 52 & $2.69^{* *}$ & $-1.83^{+}$ & 3.76 \\
\hline 19. Inferior parictal & 40 & -50 & -44 & 36 & $2.53^{*}$ & -0.41 & 2.51 \\
\hline 20. Inferior parietal & 40 & 50 & -46 & 36 & $2.59^{* *}$ & -0.97 & 3.43 \\
\hline 21. Precuneus & 7 & -10 & -52 & 40 & $2.34^{*}$ & -0.63 & 2.43 \\
\hline \multicolumn{8}{|c|}{ D. Location matching-greater rCBF reductions in young subjects } \\
\hline 22. Middle temporal & 21 & -58 & -48 & 0 & -0.10 & $-1.73^{++}$ & 2.86 \\
\hline 23. Middle temporal & 37 & 52 & -64 & 4 & -0.12 & $-1.26^{++}$ & 2.56 \\
\hline 24. Superior temporal & 22 & -34 & -54 & 20 & 0.58 & $-1.75^{++}$ & 2.75 \\
\hline 25. Middle frontal & 10 & -24 & 54 & 0 & 0.15 & $-1.15^{+}$ & 2.98 \\
\hline 26. Middle frontal & 8 & 36 & 14 & 40 & 1.39 & $-1.17^{+}$ & 2.62 \\
\hline 27. Orbital frontal & 11 & -26 & 34 & -12 & 0.62 & $-2.20^{+}$ & 2.56 \\
\hline 28. Medial frontal & 8 & -10 & 20 & 52 & 0.85 & $-2.47^{++}$ & 2.87 \\
\hline 29. Inferior parietal & 40 & -48 & -46 & 24 & -0.12 & $-3.34^{++}$ & 2.57 \\
\hline 30. Inferior parietal & 40 & 46 & -48 & 28 & 1.87 & $-2.65^{++}$ & 3.37 \\
\hline 31. Cingulate & 31 & 4 & -40 & 40 & -0.30 & $-3.16^{++}$ & 2.63 \\
\hline
\end{tabular}

Coordinates and Brodmann's areas from Talairach and Tournoux (1988). R/L (right/left) coordinate (X), negative indicates left hemisphere; $\mathrm{A} / \mathrm{P}$ (anterior/posterior) coordinate $(\mathrm{Y})$, negative indicates posterior to the zero point (located at the anterior commissure); $\mathrm{S} / \mathrm{I}$ (superior/inferior) coordinate (Z), negative indicates inferior to the AC-PC line; BA, Brodmann's area; Y Diff, matching task $\mathrm{rCBF}$ minus control task $\mathrm{rCBF}$ in young subjects (values in $\mathrm{ml} / 100 \mathrm{gm} / \mathrm{min}$ ANCOVA-adjusted and scaled to a mean of 50); O Diff = matching task minus control task $\mathrm{rCBF}$ in old subjects (same units as for young subjects); $Z, Z$ of the between-group difference. Significant activation above control task (within-group comparison): ${ }^{*}, p<0.011^{* *}, p<0.001$. Significant reduction below control task (within-group comparison): ${ }^{*}, p<$ $0.01 ; \cdots, p<0.001$

hemisphere prefrontal cortex also was seen in all selective attention conditions. If inhibition of rCBF changes is an attentional mechanism, then this mechanism may be affected by aging, since consistent reductions in those areas reduced in young subjects were not seen in the older subjects. Thus, the failure of the old subjects to show a reduction in $\mathrm{rCBF}$ relative to the control task in these areas may represent an inability to inhibit flow to these areas successfully and a reduction in the capacity to focus attention. Disinhibition may also account in part for the old subjects' increased activation of rCBF in other areas of cortex.

There were several areas of cortex where there was an agerelated difference that was specific to location matching in both experiments. One of these was medial parietal cortex, which showed greater activation in old subjects. This area of parietal cortex is not well explored in humans, but in monkeys is known to be interconnected with the frontal eye fields, the supplementary motor area, and other areas of premotor cortex (Cavada and Goldman-Rakic, 1989; Pandya and Yeterian, 1990). It is likely that medial parietal cortex plays a role in the organization of eye and body movements, as rCBF activation of this area has been found during visually guided tracking (Grafton et al., 1992). Areas of cortex in inferior parietal and inferior prefrontal regions also showed age-related differences during location matching, but not face matching, in both experiments. Inferior parietal activation has been reported during tasks of divided attention (Corbetta et al., 1991), whereas activation of left inferior frontal cortex was found during selective attention to visual features (Corbetta et al., 1991). Perhaps location matching in old subjects involves more activation of several networks, 
one involving medial parietal and dorsal prefrontal cortex for visual-motor integration, one using working memory areas of prefrontal cortex, and one or more attentional networks involving inferior parietal or inferior frontal cortex. It seems clear that age-related changes in these visual processing tasks involve frontal cortex more extensively during location matching than during face matching, although the mechanisms involved are unclear. $\Lambda$ t least part of the difference may be due to an effect of task difficulty, discussed above in terms of performance, which may increase both activation of frontal cortex and reaction time. Further experiments that systematically vary task difficulty will be necessary to resolve this question.

\section{Conclusion}

We have shown that old subjects, as well as young subjects, show a dissociation of rCBF activation during object and spatial visual processing characterized by occipitotemporal activation during face matching and occipitoparietal activation during location matching. The regions of cortex more activated in young subjects were early in the visual pathway (prestriate), possibly before the ventral-dorsal dissociation, and those more activated in the old subjects were in occipitotemporal, prefrontal, and parietal cortex. These results suggest that the neurobiological changes that underlie the performance decrements of old subjects on these visual tasks are a reduction in the processing efficiency of prestriate occipital cortex, increased utilization of one or more cortical networks to compensate for this inefficiency, and a concomitant slowing of reaction time, reflecting the increased time for information processing by these recruited areas. Some of the brain regions showing differences between young and old subjects were the same in both visual tasks; however, there were more areas of prefrontal and parietal cortex with age-related differences during location matching, and the old subjects showed evidence of greater slowing of response time during this task in Experiment II. This provides some evidence against the generalized slowing hypothesis of aging and suggests that spatial abilities may be differentially affected.

\section{References}

Allen PA, Madden DJ, Groth KE, Crozier LC (1992) Impact of age, redundancy, and perceptual noise on visual search. J Gerontol 47: P69-P74.

Alpert NM, Eriksson L, Chang JY, Bergstrom M, Litton JE, Correia JA, Bohm C, Ackerman RH, Taveras JM (1984) Strategy for the measurement of regional cerebral blood flow using short-lived tracers and emission tomography. J Cereb Blood Flow Metab 4:28-34.

Bachevalier J, Landis LS, Walker LC, Brickson M, Mishkin M, Price DL, Cork LC (1991) Aged monkeys exhibit behavioral deficits indicative of widespread cerebral dysfunction. Neurobiol Aging 12:99111.

Baddeley A (1992) Working memory. Science 255:556-559.

Baizer JS, Ungerleider LG, Desimone R (1991) Organization of visual inputs to the inferior temporal and posterior parietal cortex in macaques. J Neurosci 11:168-190.

Barbas H (1992) Architecture and cortical connections of the prefrontal cortex in the rhesus monkey. Adv Neurol 57:91-115.

Bartlett JC, Leslie JE, Tubbs A, Fulton A (1989) Aging and memory for pictures of faces. Psychol Aging 4:276-283.

Benton A (1990) Facial recognition 1990. Cortex 26:491-499.

Berg C, Hertzog C, Hunt E (1982) Age differences in the specd of mental rotation. Dev Psychol 18:95-107.

Carson RE, Berg GW, Finn RD, Patlak CS, Daube-Witherspoon ME, Stein SD, Simpson NR, Green MV, Larson SM (1987) Tomographic measurement of LCBF with high-resolution PET and $\mathrm{H}_{2}^{15} \mathrm{O}$ : comparison of methods. J Cereb Blood Flow Metab 7:S578.

Cavada C, Goldman-Rakic PS (1989) Posterior parietal cortex in rhesus monkey. II. Evidence for segregated corticocortical networks link- ing sensory and limbic areas with the frontal lobe. J Comp Neurol $287: 422-445$.

Cerella J (1985) Information processing rates in the elderly. Psychol Bull 98:67-83.

Corbetta M, Miezin FM, Dobmeyer S, Shulman GL, Petersen SE (1991) Selective and divided attention during visual discriminations of shape, color, and speed: functional analomy by positron emission tomography. J Neurosci 11:2383-2402.

Craik FIM, Morris RG, Gick ML (1990) Adult age differences in working memory. In: Neuropsychological impairments of short-term memory (Vallar G, Shallice T, eds), pp 247-267. Cambridge: Cambridge UP.

Damasio AR, Damasio H, Van Hoesen GW (1982) Prosopagnosia: anatomic basis and behavioral mechanisms. Neurology 32:331-341.

Damasio AR, Tranel D, Damasio H (1989) Disorders of visual recognition. In: Handbook of neuropsychology, Vol 2 (Goodglass $\mathrm{H}$, Damasio AR, eds), pp 317-332. Amsterdam: Elsevier.

Desimone R, Ungerleider LG (1989) Neural mechanisms of visual processing in monkeys. In: Handbook of neuropsychology, Vol 2 (Goodglass H, Damasio AR, eds), pp 267-300. Amsterdam: Elsevier.

Desimone R, Albright TD, Gross CG, Bruce C (1984) Stimulus selective properties of inferior temporal neurons in the macaque. $J$ Neurosci 4:2051-2062.

Devaney KO, Johnson HA (1980) Neuron loss in the aging visual cortex of man. J Gerontol 35:836-841.

Duara R, Grady C, Haxby J, Ingvar D, Sokoloff L, Margolin RA, Manning RG, Cutler NR, Rapoport SI (1984) Human brain glucose utilization and cognitive function in relation to age. Ann Neurol 16: 702-713.

Eslinger PJ, Benton AL (1983) Visuoperceptual performances in aging and dementia: clinical and theoretical implications. J Clin Neuropsychol 5:213-220.

Felleman DJ, Van Essen DC (1991) Distributed hierarchical processing in primate cerebral cortex. Cereb Cortex 1:1-47.

Freedman M, Oscar-Berman M (1986) Bilateral frontal lobe disease and selective delayed-response deficits in humans. Behav Neurosci 100:337-342.

Friston KJ, Passingham RE, Nutt JG, Heather JD, Sawle GV, Frackowiak RSJ (1989) Localization in PET images: direct fitting of the intercommissural (AC-PC) line. J Cereb Blood Flow Metab 9:690695.

Friston KJ, Frith CD, Liddle PF, Lammertsma AA, Dolan RD, Frackowiak RS.J (1990) The relationship between local and global changes in PET scans. J Cereb Blood Flow Metab 10:458-466.

Friston KJ, Frith CD, Liddle PF, Frackowiak RSJ (1991a) Comparing functional (PET) images: the assessment of significant change. J Cereb Blood Flow Metab 11:690-699.

Friston KJ, Frith CD, Liddle PF, Frackowiak RSJ (1991b) Plastic transformation of PET images. J Comput Assist Tomogr 15:634-639.

Frith CD, Friston K, Liddle PF, Frackowiak RSJ (1991) Willed action and the prefrontal cortex in man: a study with PET. Proc R Soc London [Biol] 244:241-246.

Fuster JM (1990) Behavioral electrophysiology of the prefrontal cortex of the primate. In: Progress in brain research, Vol 85 (Uylings HBM, Van Eden CG, De Bruin JPC, Corner MA, Feenstra MGP, eds), pp 313-323. Amsterdam: Elsevier.

Gaylord SA, Marsh GR (1975) Age differences in the speed of a spatial cognitive process. J Gerontol 30:674-678.

Goldman PS, Rosvold HE, Vest B, Galkin TW (1971) Analysis of the delayed alternation deficit produced by dorsolateral prefrontal lesions in the rhesus monkey. J Comp Physiol Psychol 77:212-220.

Goldman-Rakic PS (1987) Circuitry of primate prefrontal cortex and regulation of behavior by representational memory. In: Handbook of physiology (Plum F, Mountcastle V, eds), pp 373-417. Bethesda, MD: American Physiological Society.

Goldman-Rakic PS (1990) Cellular and circuit basis of working memory in prefrontal cortex of nonhuman primates. In: Progress in brain rescarch, Vol 85 (Uylings HBM, Van Eden CG, De Bruin JPC, Corner MA, Feenstra MGP, eds), pp 325-336. Amsterdam: Elsevier.

Grady CL, Haxby JV, Horwitz B, Ungerleider LG, Schapiro MB, Carson RE, Herscovitch P, Mishkin M, Rapoport SI (1992) Dissociation of object and spatial vision in human extrastriate cortex: age-related changes in activation of regional cerebral blood flow measured with $\left[{ }^{15} \mathrm{O}\right]$ water and positron emission tomography. J Cognit Neurosci $4: 23-34$. 
Grafton ST, Mazziotta JC, Woods RP, Phelps ME (1992) Human functional anatomy of visually guided finger movements. Brain 115: 565-587.

Haxby JV, Grady CL, Horwitz B, Ungerleider LG, Mishkin M, Carson RE, Herscovitch P, Schapiro MB, Rapoport SI (1991) Dissociation of object and spatial visual processing pathways in human extrastriate cortex. Proc Natl Acad Sci USA 88:1621-1625.

Haxby JV, Grady CL, Horwitz B, Salerno JA, Ungerleider LG, Mishkin M, Schapiro MB, Rapoport SI (1993) Dissociation of object and spatial visual processing pathways in human extrastriate cortex. In: The functional organization of human visual cortex (Gulyas B, Ottoson $\mathrm{D}$, Roland $\mathrm{P}$, eds), in press.

Herman JF, Bruce PR (1983) Adults' mental rotation of spatial information: effects of age, sex and cerebral laterality. Exp Aging Res 9:83-85.

Holden JE, Gatley SJ, Hichwa RD, Ip WR, Shaughnessy WJ, Nickles RJ, Polycn RE (1981) Cerebral blood flow using PET measurements of fluoromethane kinetics. J Nucl Med 22:1084-1088.

Iwata M (1989) Modular organization of visual thinking. Behav Neurol 2:153-165.

Koss E, Haxby JV, DeCarli CS, Schapiro MB, Friedland RP, Rapoport SI (1991) Patterns of performance preservation and loss in healthy aging. Dev Neuropsychol 7:99-113.

McGeer E, McGeer P (1976) Neurotransmitter metabolism in the aging brain. In: Aging, Vol 3 (Terry RD, Gershon S, eds), pp 389403. New York: Raven.

Mesulam M-M (1985) Attention, confusional states, and neglect. In: Principles of behavioral neurology (Mesulam M-M, ed), pp 125-168. Philadelphia: Davis.

Milner B, Petrides M (1984) Behavioral effects of frontal lobe lesions in man. Trends Neurosci 7:403-406.

Mishkin M, Ungerleider LG, Macko KA (1983) Object vision and spatial vision: two cortical pathways. Trends Neurosci 6:414-417.

Newcombe F, Ratcliff G (1989) Disorders of visuospatial analysis. In: Handbook of neuropsychology, Vol 2 (Goodglass H, Damasio AR, eds), pp 333-356. Amsterdam: Elsevier.

Owsley C, Sloane ME (1990) Vision and aging. In: Handbook of neuropsychology, Vol 4 (Nebes R, Corkin S, eds), pp 229-250. Amsterdam: Elsevier.

Pandya DN, Yeterian EH (1990) Prefrontal cortex in relation to other cortical areas in rhesus monkey: architecture and connections. In: Progress in brain research, Vol 85 (Uylings HBM, Van Eden CG, De Bmin JPC, Corner MA, Feenstra MGP, eds), pp 63-94. Amsterdam: Elsevier.

Passingham RE (1975) Delayed matching after selective prefrontal lesions in monkcys (Macaca mulatta). Brain Res 92:89-102.

Petersen SE, Fox PT, Posner MI, Mintun M, Raichle ME (1989) Positron emission tomographic studies of the processing of single words. J Cognit Neurosci 1:153-170.

Petit L, Orssaud C, Tzourio N, Salamon G, Mazoyer B, Berthoz A (1993) PET study of voluntary saccadic eye movements in humans: basal ganglia-thalamocortical system and cingulate cortex involvement. J Neurophysiol 69:1009-1017.

Petrides M, Alivisatos B, Meyer E, Evans AC (1993) Functional activation of the human frontal cortex during the performance of verbal working memory tasks. Proc Natl Acad Sci USA 90:878-882.
Plude DJ, Hoyer WJ (1986) Age and the sclectivity of visual information processing. Psychol Aging 1:4-10

Posner MI, Walker JA, Friedrich FJ, Rafal RD (1984) Effects of parietal injury on covert orienting of attention. J Neurosci 4:1863-1874.

Puglisi JT, Morrell RW (1986) Age-related slowing in mental rotation of three-dimensional objects. Exp Aging Res 12:217-220.

Rapp PR, Amaral DG (1989) Evidence for task-dependent memory dysfunction in the aged monkey. J Neurosci 9:3568-3576.

Roland PE (1982) Cortical regulation of selective attention in man. A regional cerebral blood flow study. J Neurophysiol 48:1059-1078.

Roland PE, Eriksson L, Stone-Elander S, Widen L (1987) Does mental activity change the oxidative metabolism of the brain? J Neurosci 7:2373-2389.

Rosvold HE, Szwarcbart MK, Mirsky AF, Mishkin M (1961) The effect of frontal lobe damage on delayed response performance in chimpanzees. J Comp Physiol Psychol 54:368-374.

Salthouse TA (1982) Adult cognition. An experimental psychology of lıuman aging. New York: Springer.

Salthouse TA (1987) Adult age differences in integrative spatial ability. Psychol Aging 2:254-260.

Scheiber F (1992) Aging and the senses. In: Handbook of mental health and aging (Birren JE, Sloane RB, Cohen GD, eds), pp 252-306. San Dicgo: Academic.

Sekuler R, Ball K (1986) Visual localization: age and practice. J Opt Soc Am 3:864-867.

Sekuler R, Owsley C (1982) The spatial vision of older humans. In: Aging and human visual function (Sekuler R, Kline D, Dismukes K, eds), pp 185-202. New York: Liss.

Sergent J, Ohta S, MacDonald B (1992) Functional neuroanatomy of face and object processing. A positron emission tomography study. Brain 115:15-36.

Strayer DL, Wickens CD, Braune R (1987) Adult age differences in the speed and capacity of information processing. 2. An electrophysiological approach. Psychol Aging 2:99-110.

Talairach J, Tournoux P (1988) Co-planar stereotaxic atlas of the human brain. New York: Thieme.

Ungerleider LG, Desimone R (1986) Cortical connections of visual area MT in the macaque. J Comp Neurol 248:190-222.

Ungerleider LG, Mishkin M (1982) Two cortical visual systems. In: Analysis of visual behavior (Ingle DJ, Goodale MA, Mansfield RJW, eds), pp 549-586. Cambridge, MA: MIT Press.

Ungerleider LG, Gaffan D, Pelak VS (1989) Projections from inferior temporal cortex to prefrontal cortex via the uncinate fascicle in rhesus monkeys. Exp Brain Res 76:473-484.

Vaina LM (1989) Selective impairment of visual motion interpretation following lesions of the right occipito-parietal area in humans. Biol Cybern 61:347-359.

Van Essen DC (1985) Functional organization of primate visual cortex. In: Cerebral cortex, Vol 3 (Peters A, Jones EG, eds), pp 259-328. New York: Plenum.

Wickens CD, Braune R, Stokes A (1987) Age differences in the speed and capacity of information processing. 1. A dual-task approach. Psychol Aging 2:70-78. 